\title{
The inter-relation between policy and practice for transitions from hospital to home: an ethnographic case study in England's National Health Service
}

\author{
James Shaw ${ }^{1,2^{*}}$, Pia Kontos', Wendy Martin², Christina Victor ${ }^{2}$ \\ From Health Services Research: Evidence-based practice \\ London, UK. 1-3 July 2014
}

\section{Background}

Poorly managed transitions from hospital to home for elderly patients with complex needs (commonly referred to as patient discharge) often exacerbate detriments to health and function associated with acute inpatient hospital stays. The English National Health Service introduced the Community Care (Delayed Discharges) Act in 2003 to improve the transition process, but the ways in which this policy is interpreted and applied in actual contexts of health and social care remain underexplored using qualitative methodologies. The purpose of this study was to understand the complex interrelationship between policies related to discharge from hospital and the practice of helping older people transition from hospital to home in London, United Kingdom.

\section{Materials and methods}

We used an ethnographic case study methodology to achieve a comprehensive understanding of the relationship between policy and practice for patient transitions, including the following methods: (a) observation of inter-professional team meetings in the hospital and community settings, (b) qualitative interviews with key informants including health care leaders, commissioners of care, practitioners, and patients, (c) analysis of policies at the national and local levels related to patient transitions, and (d) patient chart reviews. Data were analyzed from a critical social science perspective, and key themes were related between data sources. An overall understanding of the process of policy implementation for patient transitions were then interpreted.

\section{Results}

Findings suggest that the implementation of policies for patient transitions relied on informal practices and relationships at the individual, organizational, and interorganizational levels as opposed to formal mechanisms of control embedded in national policy (e.g., financial penalties for poor transitions). At the individual level, health care practitioners negotiated new mandates related to patient transitions in the context of existing informal relationships related to patient care decisionmaking. At the organizational level, health care managers relied on motivating and encouraging improved practice among staff as opposed to enforcing strict adherence to policy guidelines. At the inter-organizational level, healthcare leaders built informal relationships with those at partner organizations in order to build trust and encourage collaboration during the process of patient transitions.

\section{Conclusions}

This work suggests that greater attention should be paid to (a) the personal characteristics of health care leaders and practitioners and (b) the conditions of practice in health care environments that help to foster relationshipbuilding in the context of patient transitions from hospital to home. These informal relationships were found to be central to policy implementation for patient transitions.

Toronto Rehabilitation Institute, Toronto, Canada

Full list of author information is available at the end of the article 


\title{
Authors' details
}

${ }^{1}$ Toronto Rehabilitation Institute, Toronto, Canada. ${ }^{2}$ Brunel University,

London, UK

Published: 7 July 2014

\begin{abstract}
doi:10.1186/1472-6963-14-S2-P111
Cite this article as: Shaw et al:: The inter-relation between policy and practice for transitions from hospital to home: an ethnographic case study in England's National Health Service. BMC Health Services Research 2014 14(Suppl 2):P111.
\end{abstract}

Submit your next manuscript to BioMed Central and take full advantage of:

- Convenient online submission

- Thorough peer review

- No space constraints or color figure charges

- Immediate publication on acceptance

- Inclusion in PubMed, CAS, Scopus and Google Scholar

- Research which is freely available for redistribution

Submit your manuscript at www.biomedcentral.com/submit 